\title{
letters
}

\section{Letters to the Editor should be addressed to: Evidence-based Dentistry, Nature Publishing Group, 4 Crinan St, London N1 9XW, UK}

\author{
Evidence-Based Dentistry (2002) 3, 85. doi:10.1038/sj.ebd.6400131
}

Dear Sir,

Ismail AI, Sohn W. Evidence suggests more favourable outcomes with preformed metal crowns than amalgam restorations in primary molars. Evidence-based Dentistry 2002; 3:10.

We would like to respond to the critique of our paper ${ }^{1}$ by Ismail and Sohn. ${ }^{2}$ The QUOROM guidelines, ${ }^{3}$ which refer to the conduct of meta-analysis of randomised controlled trials, had not been published prior to acceptance of our manuscript. Eight out of the 10 studies evaluated for our review were retrospective. We took care to indicate to the reader that bias would inevitably be present in the papers reviewed and would be carried over into the meta-analysis, so caution should be exercised when interpreting the data. For this reason the evidence cannot be said to be 'strong'. Our conclusion was that the data demonstrated enhanced effectiveness for preformed metal crowns (PMC) versus multisurface amalgams for primary molar teeth. This outcome was apparent from the literature review of the extracted papers. We appreciate Ismail and Sohn's updated calculation using a random effects model: this typically conservative method of calculation ${ }^{4}$ yielded an odds ratio of 0.15 , and $95 \%$ confidence intervals of $0.08-0.30$, which is clear of the line-of-no-effect and indicates a clinically important outcome. Consistent results for a more favourable outcome with PMC were seen across all 10 papers. These encompassed different study settings, subject populations, operators and study duration, with a likely bias towards PMC having been placed to restore the more broken-down teeth, and amalgam being reserved for those teeth with smaller cavities. Much as a randomised controlled trial would be desirable, we doubt whether random allocation of PMC or amalgam to restore multisurface cavities in young children's primary molars would be appropriate or ethical.

Yours faithfully

Ros C Randall, 3M Centre, St Paul MN, USA

Thijs MA Vrijhoef

University of Nijmegen, The Netherlands

Nairn HF Wilson

Guy's, King's and St Thomas Dental Institute, London, UK

1. Randall RC, Vrijhoef MMA, Wilson NHF. Efficacy of preformed metal crowns vs amalgam restorations in primary molars: a systematic review. J Am Dent Assoc 2000; 131:337-343.

2. Ismail Al, Sohn W. Evidence suggests more favourable outcomes with preformed metal crowns than amalgam restorations in primary molars. Commentary. Evidence-based Dentistry 2002; 3:10.

3. Moher D, Cook DJ, Eastwood S, Olkin I, Rennie D, Stroup DF. Improving the quality of reports of meta-analyses of randomized controlled trials: the QUOROM statement. Lancet 1999; 354:1896-1899.

4. Lau J, loannidis JPA, Schmid CH. Summing up evidence: one answer is not always enough. Lancet 1998; 351:123-127. 